\title{
SALA DE AULA INVERTIDA UTILIZANDO O CLASSROOM PARA O ESTUDO DA CONSERVAÇÃO DE ENERGIA MECÂNICA
}

\author{
Charles Bruno da Silva Melo1; Janilse Fernandes Nunes ${ }^{2}$
}

\section{RESUMO}

Este artigo apresenta uma experiência de ensino vivenciada pelo primeiro autor, tendo como contexto o ensino remoto provocado pela pandemia da COVID-19 em uma escola privada de Santa Cruz do Sul/RS utilizando como método a Sala de Aula Invertida a partir do Google Classroom para o estudo da conservação de Energia Mecânica com uma turma de 34 estudantes do $2^{\circ}$ ano do Ensino Médio. Foram desenvolvidas atividades síncronas e assíncronas durante um mês. O modo síncrono constituiu-se por encontros semanais de 1h30min via Google Meet e o assíncrono foi caracterizado pelo envio de tarefas semanais, ambos desenvolvidos por meio do Google Classroom._Diante disso, foi possível constatar que a Sala de Aula Invertida é uma aliada no processo de aprendizagem nas aulas remotas, promovendo aprofundar mais os estudos e discussões, desenvolvendo um ambiente para atividades em grupos, trabalho coletivo e exploração de diferentes ferramentas digitais estimulando a colaboração e criatividade.

Palavras-chave: Aula remota; Ensino de Física; Metodologia ativa.

Eixo Temático: Educação, Cultura e Comunicação (ECC)

\section{INTRODUÇÃO}

A pandemia provocada pelo vírus da COVID-19, mesmo se tratando de uma questão de saúde pública, afetou diversos campos, trazendo consequências também em relação ao ensino e a educação de modo geral. Com a orientação do isolamento social pela Organização Mundial da Saúde (OMS) para conter o avanço da doença, as aulas presenciais em todos os níveis de ensino tiveram de ser interrompidas abruptamente.

\footnotetext{
${ }^{1}$ Doutorando do Programa de Pós-graduação em Ensino de Ciências e Matemática (PPGECIMAT) da Universidade Franciscana (UFN). E-mail: xarlesdemelo@yahoo.com.br.

2 Docente do Programa de Pós-Graduação em Ensino de Ciências e Matemática da Universidade Franciscana (UFN). E-mail: janilsenunes@gmail.com.
} 
A parada forçada fez com que as instituições de ensino se organizassem de modo rápido tendo como intuito dar continuidade ao processo de aprendizagem dos estudantes. Desse modo, inevitavelmente, o uso de tecnologias e diferentes plataformas digitais, como o Google Classroom, se tornaram fundamentais para o andamento das atividades escolares.

O atual contexto, com todas as dificuldades inerentes, propiciou que as atividades escolares fossem realizadas de modo remoto, uma vez que, o termo remoto significa distante no espaço e se refere a um distanciamento geográfico, mas não temporal. Conforme António Moreira e Schlemmer (2020, p. 8):

O Ensino Remoto ou Aula Remota se configura então, como uma modalidade de ensino ou aula que pressupõe o distanciamento geográfico de professores e estudantes e vem sendo adotada nos diferentes níveis de ensino, por instituições educacionais no mundo todo, em função das restrições impostas pelo COVID-19, que impossibilita a presença física de estudantes e professores nos espaços geográficos das instituições educacionais.

Sendo assim faz-se é necessária a utilização de um ambiente virtual que dê continuidade aos processos de ensino e de aprendizagem visando atender 0 desenvolvimento dos estudantes, com vista as habilidades previstas na Base Nacional Comum Curricular (BRASIL, 2017). Uma possibilidade é o Google Classroom, que faz parte do G Suite for Education, onde o professor organiza as turmas e direciona diferentes trabalhos, usando ou não as demais ferramentas do Google Apps.

Outra mudança a ser considerada nas aulas remotas é a redução do tempo, pois elas se configuram mais curtas que no modo presencial devendo-se considerar a exposição do aluno frente às telas por um período maior que o comum. Para compensar essa redução de carga horária, muitas escolas adotaram atividades assíncronas promovendo um ambiente propício para o método de ensino da Sala de Aula Invertida.

Segundo Berrett (2012, p. 14), na sala de aula invertida:

O professor passa a mediar e orientar as discussões e a realização das atividades, agora executadas em sala de aula, considerados os conhecimentos e conteúdos acessados previamente pelo estudante, isto é, fora do ambiente da sala de aula. Agora o professor pode dedicar o seu tempo de sala de aula, na presença dos estudantes, para consolidar conhecimentos para orientá-lo, esclarecer as suas dúvidas e apoiá-lo no desenvolvimento do seu aprendizado. É, portanto, uma estratégia que propõe mudar alguns 
elementos do ensino presencial, sugerindo uma alternativa à lógica tradicional.

É nesse cenário que será descrita uma experiência de aulas remotas vivenciadas pelo primeiro autor em uma escola privada de Santa Cruz do Sul/RS, utilizando como método a Sala de Aula Invertida a partir do Google Classroom para o estudo da conservação de Energia Mecânica. O processo foi mediado com uma turma do $2^{\circ}$ ano do Ensino Médio.

\section{ORIENTAÇÕES}

\subsection{Google Classroom como ambiente virtual para as aulas remotas}

No ensino remoto, o ensino presencial migra para os meios digitais, em rede. Embora ocorra um distanciamento geográfico, buscam-se compartilhar conhecimentos, entre professor e estudante, conectados ao mesmo tempo. Desse modo, o espaço pedagógico da sala de aula física é substituído por uma sala de aula digital.

Envolve uso de soluções de ensino totalmente remotas idênticas às práticas dos ambientes físicos, sendo que o objetivo principal nestas circunstâncias não é recriar um ecossistema educacional online robusto, mas sim fornecer acesso temporário e de maneira rápida durante o período de emergência ou crise. (ANTÓNIO MOREIRA; SCHLEMMER, 2020, p. 9)

Nesse processo pode-se dizer que a comunicação tem como protagonista o professor que realiza as aulas por meio de vídeo-aulas ou por meio de sistemas de webconferência promovendo uma lógica de controle, pois tudo o que é concebido e disponibilizado é registrado, gravado e pode ser acessado e revisto posteriormente. Portanto, é fundamental um ambiente virtual que contemple essas características para que ocorram as aulas remotas.

Nos últimos anos a Google vem lançado e melhorado diversas ferramentas no campo da educação, com destaque para o Google Classroom. Para Araujo (2016) o ambiente se configura como uma sala virtual online de fácil utilização possibilitando a integração de diversas ferramentas disponibilizadas no G Suite for Education como: Gmail, Google Drive, Hangouts, Google Docs, Google Forms e Google Meet. Além do uso em computadores a plataforma ainda conta com a possibilidade de ser utilizada em smartphones e tablets, por meio de aplicativo. 
EDUCAÇÃO, SAÚDE

ETECNOLOGIA

26 A 28 DE OUTUBRO DE 2021

De acordo com Witt (2015, p. 3), "G Suite for Education oferece um conjunto de ferramentas de comunicação e produtividade destinadas a promover a colaboração e criatividade". O autor acrescenta ainda que, o "desenvolvimento das habilidades de: comunicação, colaboração, pensamento crítico e criatividade", são potencializadas ao utilizar as tecnologias do século XXI. Tais habilidades estão contempladas dentro das competências gerais previstas na BNCC (BRASIL, 2017, p. 9):

\footnotetext{
* Pensamento Científico, Crítico e Criativo: Exercitar a curiosidade intelectual e recorrer à abordagem própria das ciências, incluindo a investigação, a reflexão, a análise crítica, a imaginação e a criatividade, para investigar causas, elaborar e testar hipóteses, formular e resolver problemas e criar soluções (inclusive tecnológicas) com base nos conhecimentos das diferentes áreas.

* Comunicação: Utilizar diferentes linguagens - verbal (oral ou visual-motora, como Libras, e escrita), corporal, visual, sonora e digital -, bem como conhecimentos das linguagens artística, matemática e científica, para se expressar e partilhar informações, experiências, ideias e sentimentos em diferentes contextos e produzir sentidos que levem ao entendimento mútuo. *Cultura Digital: Compreender, utilizar e criar tecnologias digitais de informação e comunicação de forma crítica, significativa, reflexiva e ética nas diversas práticas sociais (incluindo as escolares) para se comunicar, acessar e disseminar informações, produzir conhecimentos, resolver problemas e exercer protagonismo e autoria na vida pessoal e coletiva.

* Argumentação:Argumentar com base em fatos, dados e informações confiáveis, para formular, negociar e defender ideias, pontos de vista e decisões comuns que respeitem e promovam os direitos humanos, a consciência socioambiental e o consumo responsável em âmbito local, regional e global, com posicionamento ético em relação ao cuidado de si mesmo, dos outros e do planeta.

* Responsabilidade e Cidadania: Agir pessoal e coletivamente com autonomia, responsabilidade, flexibilidade, resiliência e determinação, tomando decisões com base em princípios éticos, democráticos, inclusivos, sustentáveis e solidários.
}

Para Silva (2018) alguns dos benefícios do Google Classroom estão na fácil configuração e uso, redução de tempo e papel, maior organização, comunicação e feedback aprimorados, auxílio de uma gama de aplicativos, acessível, seguro e gratuito. Consequentemente, essa plataforma possibilita a interação, organização e a orientação ao ritmo de estudo do estudante, importante para o processo de aprendizagem.

Desse modo, o Google Classroom pode ser uma possibilidade interessante de ambiente virtual para o desenvolvimento de aulas remotas em função da gama de ferramentas associadas a ele. Concordando com Pereira, Schmitt e Dias (2007) que o ensino aprendizagem é mais dinâmico e interativo no ambiente virtual de 
EDUCAÇÃO, SAÚDE

ETECNOLOGIA

26 A.28 DE OUTUBRO DE 2021

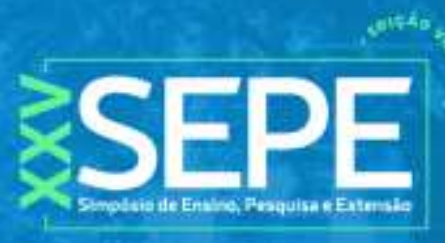

aprendizagem, graças à diversidade de interfaces e ferramentas utilizadas no ambiente, proporcionando ao aluno múltiplas formas de aprendizagem.

\subsection{Sala de Aula Invertida}

Com a implementação das aulas remotas ocorreram reduções na carga horária das disciplinas dando possibilidades para o uso implementação da Sala de Aula Invertida como aliada para os processos de ensino e de aprendizagem.

A Sala de Aula Invertida é formada, basicamente, por dois elementos: um que requer interação humana (atividades em sala de aula), ou seja, a ação; e outro que é desenvolvida por meio do uso das tecnologias digitais (atividades fora da sala de aula). No atual cenário, as atividades em sala de aula e fora dela se dão em um ambiente virtual de aprendizagem, porém de modo síncrono (em sala de aula) compartilhando o mesmo tempo e assíncrono (fora da sala de aula) por meio de atividades complementares. Pode assim se definir:

A sala de aula invertida prevê o acesso ao conteúdo antes da aula pelos alunos e o uso dos primeiros minutos em sala para esclarecimento de dúvidas, de modo a sanar equívocos antes dos conceitos serem aplicados nas atividades práticas mais extensas no tempo de classe. Em classe, as atividades se concentram nas formas mais elevadas do trabalho cognitivo: aplicar, analisar, avaliar, criar, contando com o apoio de seus pares e professores. (BERGMANN; SAMS, 2016, p. 13)

Nesse modelo, é possível aproveitar melhor o tempo do professor, uma vez que os estudantes já vão preparados para a aula, possibilitando desta forma melhorar a qualidade da discussão do tema proposto.

Adotar as ferramentas tecnológicas e o ensino assíncrono, que caracterizam a sala de aula invertida, com uma abordagem voltada para os alunos, para decidir o que lecionar, tende a criar um ambiente estimulante para a curiosidade. Não se precisa mais perder tempo reapresentando conceitos já bem conhecidos, que apenas devem ser relembrados, nem usar o valioso tempo em sala de aula para transmitir novo conteúdo (BERGMANN; SAMS, 2016, p. 15).

Outro ponto positivo é o desenvolvimento de atividades em grupos, melhorando o relacionamento interpessoal dentro da turma, promovendo que as dúvidas sejam sanadas mais facilmente e de forma coletiva, muitas vezes resultando em melhor compreensão do conceito em estudo. 
Moran (2014) considera que o modelo da Sala de Aula Invertida é um dos mais interessantes da atualidade para combinar tecnologia com metodologia de ensino, pois foca no virtual o que é informação básica e, na sala de aula, atividades criativas e supervisionadas.

Não se inverte apenas a estrutura do processo de aprendizagem nesse método, mas também transforma os papéis de estudantes e dos professores. Muito diferente do modelo tradicional, a aula está centrada nos estudantes, em que eles têm o compromisso de estudar os materiais disponibizados e fazer perguntas adequadas, buscando o professor para auxiliá-lo na compreensão dos conceitos. Desse modo, o professor está presente para dar o feedback de modo a sanar as dúvidas e corrigir os erros, pois sua função é mediar o processo ampliando os conceitos e não mais transmitindo informações (BERGMANN; SAMS, 2016).

Conforme Schneider et al (2013) apontam a Sala de Aula Invertida como:

[...] possibilidade de organização curricular diferenciada, que permita ao aluno o papel de sujeito de sua própria aprendizagem, reconhecendo a importância do domínio dos conteúdos para a compreensão ampliada do real e mantendo o papel do professor como mediador entre o conhecimento elaborado e o aluno.

A utilização da sala de aula invertida como um método é uma mudança paradigmática nos processos de ensino e de aprendizagem, em que a atuação do professor e do estudante se configura por uma articulação dialética com possibilidades de potencializar a problematização sobre a temática estudada.

\section{RELATO DE EXPERIÊNCIA}

As aulas remotas foram adotadas na escola em meados de março, devido ao decreto estadual que determinava a suspensão das aulas presenciais. Nessa dinâmica foi orientado que as aulas fossem por meio de atividades síncronas e assíncronas. O modo síncrono constituiu-se por encontros semanais de 1h30min via Google Meet seguindo os mesmos horários das aulas presenciais. Para contemplar o modo assíncrono, adotado com o intuito de complementar a redução da carga horária das disciplinas, foi caracterizado pelo envio de atividades semanais.

Nesse contexto, foi utilizado a Sala de Aula Invertida para o estudo da conservação da Energia Mecânica em uma turma do segundo ano do Ensino Médio 
de uma escola privada, na qual o primeiro autor é regente de classe, no município de Santa Cruz do Sul/RS, com 34 alunos. A experiência foi desenvolvida nos meses de abril e maio.

Inicialmente, foram enviados como materiais para estudo, slides e um vídeo para os alunos de forma antecipada ao encontro semanal, abordando conceitos que envolviam a conservação da Energia Mecânica por meio de uma problemática tendo como tema o movimento de um carrinho em uma montanha-russa. Na Figura 1 é apresentada a parte inicial desses materiais.

Figura 1: Slides e vídeo enviado aos alunos antecipadamente.

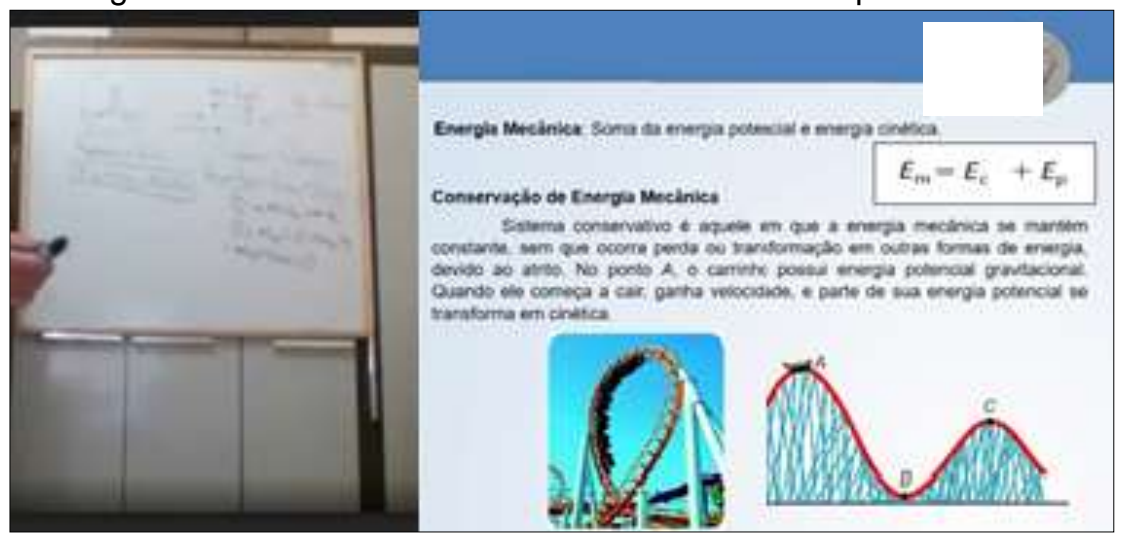

Fonte: Print screen do Google Classroom

De modo síncrono, portanto no encontro semanal, foi discutido em grupos a problemática envolvendo a montanha-russa: "Por que normalmente no início do percurso em uma montanha-russa tem uma subida?". Grande parte da turma, concluiu que era necessário ter a subida no início do percurso para adquirir energia potencial gravitacional em função da diferença de altura e que o movimento iria depender unicamente da ação gravitacional que 'puxaria' o carrinho para baixo sendo transformada em energia cinética.

Com essa constatação, foi questionado se toda a energia potencial gravitacional nesse processo seria transformada em energia cinética. Nessa análise, eles afirmaram que não, pois teria o atrito dos trilhos com as rodas do carrinho, sendo assim a situação se caracterizava por um sistema dissipativo, ocorrendo a transformação em outras diferentes formas de energia além da cinética, como por exemplo, a térmica e sonora. Utilizando essa situação, foi formalizado o conceito envolvendo a conservação da Energia Mecânica. 
$\mathrm{Na}$ sequência, como atividade assíncrona foi enviado um roteiro com orientações para que os alunos explorassem a simulação "Energia na pista de skate" disponível na plataforma $\mathrm{PhET}^{3}$. O intuito dessa atividade era de que os estudantes pudessem verificar os conceitos estudados anteriormente na simulação envolvendo sistemas conservativos e dissipativos.

Tendo os estudantes já explorado a simulação, no encontro semanal posterior, eles foram desafiados a resolver algumas questões a partir do uso da simulação afim de discutir e debater, bem como diagnosticar os conceitos estavam claros referentes ao estudo realizado sobre a conservação de Energia Mecânica sendo realizada em grupos de cinco e quatro componentes. Essa atividade foi disponibilizada por meio de um QR CODE como ilustra a Figura 2.

Figura 2: Atividades de exploração da simulação "Energia na pista de skate". Fonte: próprio autor.

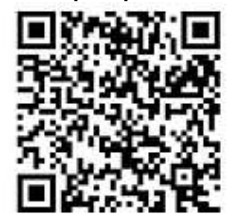

$\mathrm{Na}$ primeira questão, foi solicitado que o skatista fosse posicionado em diferentes alturas e pistas. Posteriormente, solicitado se existia alguma relação entre a altura inicial do skatista e a altura máxima que ele conseguia alcançar na pista, verificando em que pontos a energia potencial gravitacional foi mais intensa.

Maior parte dos estudantes conseguiu responder corretamente essa pergunta, relacionando as transformações entre energia cinética e potencial gravitacional no sistema conservativo e dissipativo, exemplificado pela resolução de um grupo na Figura 3.

Figura 3: Atividade I de exploração da simulação "Energia na pista de skate". Fonte: Print screen da resolução do grupo A

\footnotetext{
${ }^{3}$ Disponivel em: https://phet.colorado.edu/sims/html/energy-skate-park-basics/latest/energy-skate-parkbasics_pt_BR.html . O PhET oferece simulações de matemática e ciências divertidas, interativas, grátis, baseadas em pesquisas mantido pela universidade do Colorado - EUA.
} 


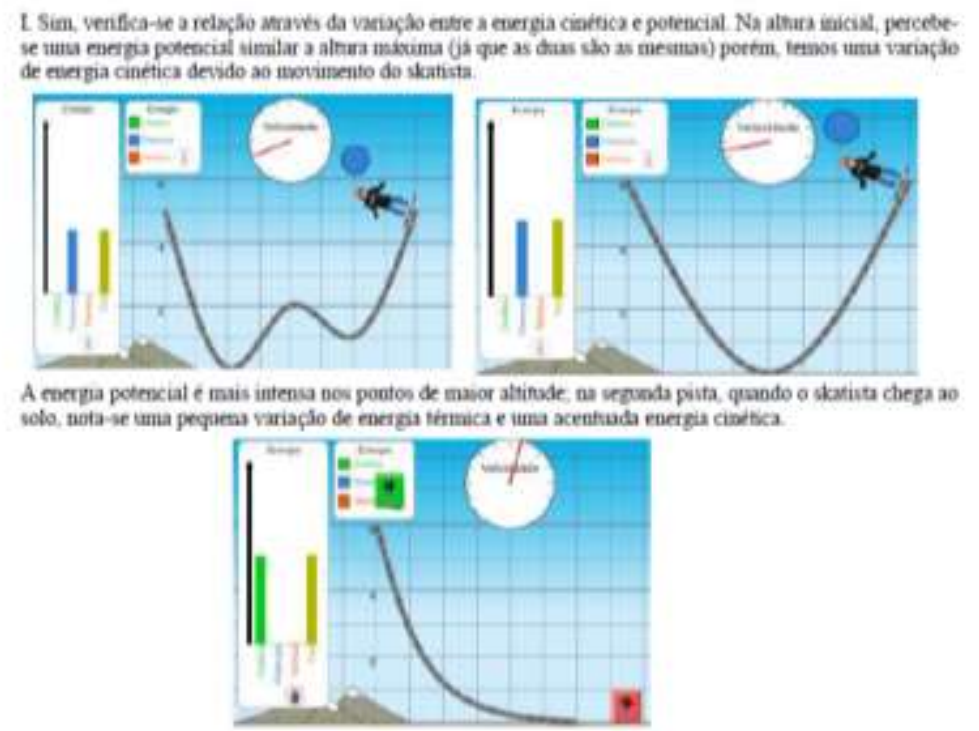

No segundo questionamento, buscou-se analisar em quais pontos da trajetória do skatista a velocidade foi máxima, bem como se existia uma relação entre a velocidade e a energia do sistema, além da massa do skatista.

A turma conseguiu compreender claramente as relações entre a velocidade e energia do sistema, pois apontou que a velocidade máxima do skatista ocorreria nos pontos de descida da rampa, devido a transformação de energia potencial gravitacional em cinética, que surge por meio do movimento. Ao se aumentar a massa do skatista, tem-se uma energia cinética maior, da mesma forma, diminuindo a sua massa, uma energia cinética menor considerando a mesma altura inicial da pista em ambos os casos.

Nessa questão, era necessário considerar o atrito nas situações apresentadas nas questões anteriores e abordando se o movimento ocorreria da mesma forma. Os estudantes puderam perceber que as características do movimento mudam com o atrito, e que o movimento cessa em algum instante. A energia cinética e potencial gravitacional diminui aos poucos até se tornarem nulas, enquanto a térmica permanece alta até o final do movimento.

Continuando essa observação na simulação em relação à influência do atrito no movimento, foi alterada sua intensidade enquanto o skatista se movimentava na pista de modo a observar a relação entre as energias envolvidas no fenômeno. Eles constataram que, ao aumentar o atrito, ocorre uma dificuldade da movimentação do 
skatista na pista e, desse modo, a energia térmica no processo é maior e as energias, potencial gravitacional e cinética, vão diminuindo, pois se transformam em térmica, além de notarem que o movimento do skatista para.

Finalizando a atividade, foi proposto que os alunos utilizassem a imaginação e criatividade para construção de uma nova pista analisando o movimento do skatista em um sistema conservativo e dissipativo de modo que fosse relacionado os conceitos teóricos estudados anteriormente. Na Figura 4 é ilustrada a análise realizada por um dos grupos.

Figura 4: Atividade V explorando a simulação "Energia na pista de skate". Fonte: Print screen da resolução do grupo B.

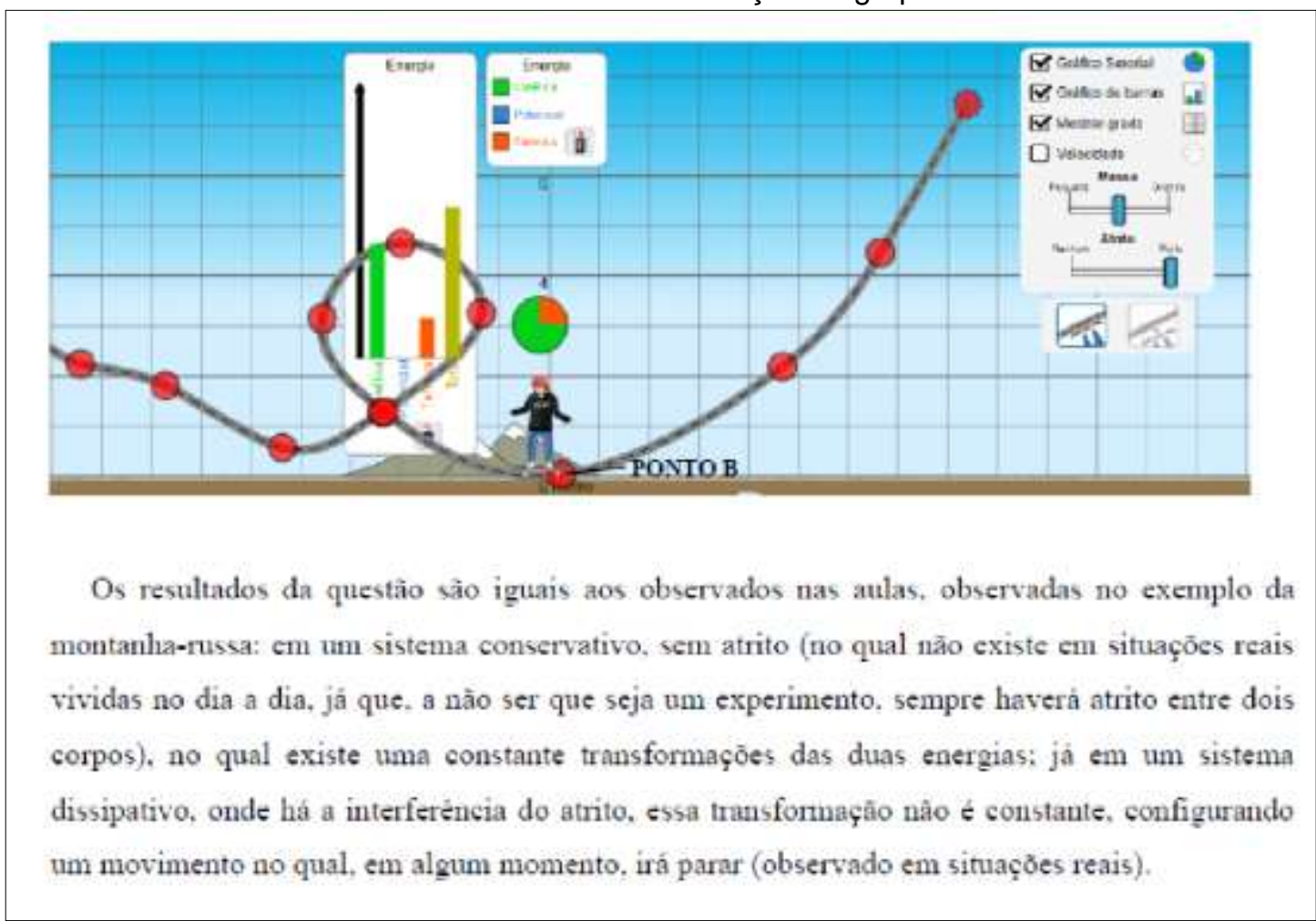

\section{CONSIDERAÇÕES FINAIS}

A Sala de Aula Invertida formada basicamente por dois elementos: um que requer interação humana, no caso das aulas remotas via Google Classroom, os encontros semanais por meio do Google Meet, e outro que é desenvolvido por meio do uso das tecnologias digitais fora da sala de aula, as atividades assíncronas. 
Diante disso, com o trabalho desenvolvido foi possível constatar que a Sala de Aula Invertida é uma aliada no processo de aprendizagem nas aulas remotas. Em função inicialmente a reduções na carga horária das disciplinas e a necessidade de aproveitar os encontros semanais (síncrono) para aprofundar mais os estudos e discussões, uma vez que, os alunos já vão preparados para a aula, possibilitando desta forma melhorar a participação e a qualidade de abordagem do tema proposto.

Outro ponto positivo é o desenvolvimento de atividades em grupos, nesse caso, além de melhorar o relacionamento interpessoal e a forma de trabalho coletivo, possibilitou a exploração de diferentes ferramentas digitais estimulando a colaboração e criatividade, além da possibilidade do desenvolvimento das habilidades de comunicação, colaboração, pensamento crítico e criatividade por parte dos estudantes.

Nesse método de Sala de Aula Invertida se evidencia a questão da responsabilidade, autonomia e protagonismo do aluno durante as aulas remotas, refletindo diretamente na organização das atividades, pois os educandos têm o compromisso de estudar os materiais disponibilidades e fazer perguntas adequadas, buscando que o professor durante os encontros semanais possa auxiliar na compreensão dos conceitos estudados. Desse modo, o professor se tornou um mediador dos processos de ensino e de aprendizagem, enquanto o estudante assume o papel ativo e autônomo na construção do seu próprio conhecimento.

\section{AGRADECIMENTOS}

O presente trabalho foi realizado com apoio da Coordenação de Aperfeiçoamento de Pessoal de Nível Superior - Brasil (CAPES) - Código de Financiamento 001.

\section{REFERÊNCIAS}

ANTÓNIO MOREIRA, J., SCHLEMMER, E. (2020). Por um novo conceito e paradigma de educação digital onlife. Revista UFG, 20(26).

ARAUJO. H. M. C. O uso das ferramentas do aplicativo "GOOGLE SALA DE AULA" no ensino da matemática. 83f. Dissertação (Mestrado). Programa de 
Mestrado Profissional em Matemática em rede Nacional.Universidade Federal de Goiás, 2016.

BERGMANN, J.; SAMS, A. Sala de aula invertida - uma metodologia ativa de aprendizagem. 1. ed. Rio de Janeiro. 2016.

BERRETT, Dan. Howflippingtheclassroomcan improve thetraditionallecture. The EducationDigest, v. 78, n. 1, p. 36, 2012.

BRASIL. Base Nacional Comum Curricular. Brasília: MEC, 2017. Disponível em: http://basenacionalcomum.mec.gov.br/images/BNC C_20dez_site.pdf. Acesso em: 10 jul. 2020.

HALLIDAY, D.; RESNICK, R.; E. WALKER, J. Fundamentos da Física: Mecânica. V. 1. 4ㄹ. Ed.Rio de Janeiro: Livros Técnicos e Científicos,1996.

HORTA, L. et al. Conservação de Energia Eficiência Energética de Equipamentos e Instalações. Itajubá, MG. Fupai, 2006.

JEWETT, J. W., Jr. Energy andtheConfusedStudent IV: A Global Approach to Energy. The PhysicsTeacher, 46, 210, 2008.

MORAN, J. M. Nova personalidade [25 out. 2014]. Brasília: Correio Braziliense. Brasília. Entrevista concedida para Olivia Meireles.

PEREIRA, A. T. C.; SCHMITT, V.; DIAS, M. R. A C. Ambientes Virtuais de Aprendizagem. In: PEREIRA, Alice T. Cybis. (orgs). AVA - Ambientes Virtuais de Aprendizagem em Diferentes Contextos. Rio de Janeiro: Editora Ciência Moderna Ltda., 2007.

SCHNEIDER, E.; et al. Sala de aula invertida em EAD: uma proposta de blendedlearning. Revista Intersaberes. vol. 8, n.16, p.68-81, jul. - dez. 2013. Disponível em: http://www.grupouninter.com.br/intersaberes/index.php/revista/article/view/4 99. Acesso em: 2 jul. 2020.

SILVA, E.C.S. O Google Sala de aula como interface de aprendizagem no ensino superior. In: SIMPOSIO INTERNACIONAL DE EDUCAÇÃO E COMUNICAÇÃO. (9º), 2018, Aracaju. SIMEDUC. Disponível em:https://eventos.set.edu.br/index.php/simeduc/article/viewFile/95 72/4164. Acesso em: 5 jul. 2020.

WITT, D. Accelerate Learning with Google Apps for Education. [2015]. Disponível em: $\quad<$ https://danwittwcdsbca.wordpress.com/2015/08/16/accelerate-learning-withgoogle-apps-for-education/>. Acesso em: 8 jul. 2020. 